\title{
Last resort employees: Older workers’ perceptions of workplace discrimination
}

\begin{abstract}
Like other countries, Australia is becoming increasingly reliant upon an aging workforce. Yet, much literature positions older workers as 'last resort' employees: held in low esteem by employers whose preference for youth over age extends into decision-making about workplace engagement and support. As part of a broader study on maintaining the competence of older workers, we investigated the extent to which such employees (aged 45 or more) perceived they were discriminated against because of their age, including in regard to access to training and promotion opportunities, and to job security. Against expectations arising from the literature, informants reported little in the way of explicit age-related bias in their employment, opportunities for advancement and further development. Although the sample has particular characteristics and featured paraprofessional and professional workers, the contrast is noteworthy between what is reported in the literature and often premised on surveys, and our data was based on interviews. The findings indicate the need to be wary of making easy generalisations about the extent to which older workers are discriminated against in the workplace, particularly in certain types of industries and occupations, while at the same time acknowledging that such discrimination does exist. In addition, we found a range of nuanced responses that suggest there are tensions between discriminations policies and practice that are a challenge for human resource development professionals.
\end{abstract}

\section{Key words}

Older workers

Employer support

Employability

Age-bias

Employer bias

Sustaining work capacities

\section{Older workers and work}

As in many other countries, it is predicted that over the next 40 years or so, Australia will have an increasing proportion of people aged 65 or more, and a decreasing number of young people and, hence, new workforce entrants. Assuming sustained low fertility and increasing life expectancy by 2050 , some $26 \%$ of the population are predicted to be in the older working age bracket, compared to 15\% aged 0 to 14 years (Australian Bureau of Statistics (ABS), 2008). This changing age profile has a range of social and economic implications. A key concern for government and industry is a potential labour shortage and, therefore, a potential decline in productivity and competitiveness. 
According to the ABS (2008, 4), the proportion of the working age population in Australia will decrease from around $67 \%$ in 2010 to some 59\% in 2050, if present rates of retirement continue.

Sustaining the employability of mature age workers is seen as one way of maintaining a sufficiently productive labour force (Treasury, 2004, 15). However, although this goal may seem an appropriate policy response, the literature consistently reports negative attitudes from Australian employers and those in other countries about employing and re-training mature age workers. Hence, despite their apparent potential contributions to the workforce, older workers appear not to be sufficiently valued by key workplace decision-makers to fully contribute to and be supported in securing the kinds of goals their workplaces want realised. As part of a broader study into sustaining the competence of older workers, this paper reports on the perceptions of a cohort of employees aged 45 (the age at which the ABS classifies them as 'mature age' workers) or more about the extent to which they experienced age bias in their workplaces. A key concern here is the degree to which these workers are regarded as having the capacities for 'employability': to be employable and competent, and to adapt and respond effectively to emerging workplace challenges.

\section{Older workers: a view from the Australian literature}

The literature about older workers prospects for employability projects a rather consistent and persistent sentiment: that they are considered 'last resort' employees; that is, to be employed when all other options have been exhausted. A review of research published between 1989 and 2000 (Bittman, Flick \& Rice, 2001, 39) captures the first sentiment. They conclude:

Australian studies report that older workers are valued for their skills, experience, loyalty, corporate knowledge, commitment, strong work ethic, reliability, and low absenteeism. At the same time, employers regard older workers as less adaptable to change, less productive, hard to train, inflexible, less motivated, a risky investment and with potential poor health.

In all, these authors concluded (p. 40) that 'negative employer attitudes are based in stereotypes and age discrimination and operate to limit the labour market experience and opportunities of older 
workers'. This conclusion is reinforced by Gringart, Helmes and Speelman's (2005, 96) finding from a survey of 128 'hiring decision-makers' in businesses of up to 50 employees that those managers were generally unlikely to hire older workers because:

Older workers were viewed as being less adaptable to new technology, less interested in technological change and less trainable, as well as being less ambitious, less energetic, less healthy, less creative and not as physically strong. They were thought to have impaired memory, to be less mentally alert, and less flexible. Finally, older workers were considered inferior to younger workers in their likelihood to be promoted.

Indeed, an Australian study of attitudes towards older workers in the mid 1990s found that 'regardless of the perceived more positive qualities of older workers ..., employers appear to prefer to recruit employees in the younger age groups for most employee categories' with 'minimal interest in recruiting anyone over 45 years for any job ... and no preference for anyone 56 years or older' (Steinberg, Donald, Najman, \& Skerman, 1996, 157). So, despite the growing recognition of a looming labour shortage and an increased reliance on older workers, such attitudes appear to be stubbornly resistant to change. For instance, more recently, a guide by the Business Council of Australia (BCA, 2003, 12) identified numerous 'readily accepted negative stereotypes of mature-age workers’.

Encel (2003, 3) claims that negative attitudes towards older workers such as these may well contribute to the widespread 'culture' of early retirement in Australia where workforce participation by those over 55 year is considerably lower than in many other OECD countries (ABS, 2007), although the Reserve Bank of Australia (RBA) note this level has recently increased slightly (RBA, 2007). Certainly, enduring sentiments such as these are likely to position older workers as undesirable employees. Indeed, the Business Council of Australia (BCA) $(2003,6)$ worried that these stereotypes underpin discrimination and limit working and business opportunities, and suggested that employers should support older workers' participation not only to maintain the skills and experience base, but also 'to better align the work force with an ageing customer base'. Further, the BCA also claims $(2003,18)$ voluntary retirement is used as a workforce management tool, often 
based on age alone, and without consideration to workers' skill and experience profiles. Hence, in this way, Encel $(2003,4)$ warns that age discrimination is 'commonly covert and evasive and easily masked'. From a review of submissions to an Australian House of Representatives inquiry into older workers' unemployment, Bittman et al $(2001,46)$ reported that older workers were consistently told they were 'over qualified for lower positions and under qualified for higher positions'.

The BCA $(2003,11)$ also suggests that recruitment agencies, rather than the companies they represent, serve these sentiments by practising 'ageism' when selecting job applicants, a claim denied by the agencies (Hovenden, 2004). Further, several such agencies promote mature age employment, and one of them commissioned a report on the implications of an ageing population for the Australian workforce which described ageism as 'a particularly insidious form of discrimination' (Jorgensen, 2004, 13). Consistent with this discriminatory behaviour, Drew and Drew (2005) found the perceived opportunity cost of losing potential long term younger employees was preferred over recruiting those with limited time left in the workforce. Yet, in doing so, these researchers identify factors other than just age bias alone: those from the economic dimension. They found that, overall, the 38 organisations they surveyed had a 'fairly positive' view of mature age workers, but their practice often differed from their stated values.

The tension identified above about older workers, indicates factors other than age per se are at play here. For example, Ranzijn $(2005,1)$ claims that 'in general, age discrimination is not a function of a negative attitude towards older workers. Instead, it is premised on an implicit cost/benefit analysis', which has not been questioned or tested. The OECD $(2006,10)$ also noted that employers' attitudes towards older workers is premised on 'wages and non-wage labour costs that rise more steeply with age than productivity' and also the 'shorter expected pay-back periods on investments in the training of older workers as well as their lower average educational attainment'. The issues raised in the BCA (2003) and Jorgensen (2004) indicate patterns of decision-making that are shaped by implicit assumptions regardless of whether they are well founded or not. So, more than age bias alone, factors associated with employability, performance, 
trainability and return on investment may also implicitly shape decisions about the continued employment of older workers, and appear to position them as workers of last resort.

Indeed, as Duncan (2003, 104) concludes, employer attitudes towards older workers is a complex issue, and suggested that research may be 'searching for proof of ageism rather than testing for its extent or influence’. For instance, a New Zealand study of 94 low-skilled workers aged 50 or more, employed in three meat processing plants and a knitting mill, reported they experienced no age-related pressure from managers or supervisors (McGregor \& Gray, 2003, 1). Similarly, Howell, Buttigieg and Webber $(2006,6)$ concluded that senior management support for diversity and effective utilisation of older workers in the retail workforce resulted in positive attitudes from other managers. To further complicate the issue, there is evidence that negative perceptions are held by older workers themselves, thereby perhaps 'reflecting the deep-seated nature of societal beliefs’' (McGregor, 2007, 12).

Yet, beyond what employers believe about older workers is the extent to which they act upon those beliefs. The dichotomy of employer views is summed up in two competing models (Yeatts, Folts \& Knapp, 2000): the depreciation model, which proposes that the value of workers declines as they move towards retirement age, and the conservation model, which considers all employees regardless of age as 'long-lasting organisational assets, worthy of investment' (Claes \& Heymans, 2008, 96). It would seem that the former view is that most frequently captured in the literature. Clearly, employer perceptions of older workers' competence are important. This is because, as Taylor and Walker $(1998,644)$ note, they 'may directly influence not only their prospects for gaining employment, but also their prospects for development and advancement within an organisation’. They may also influence employees’ retirement decisions.

Four main themes emerge from the research we reviewed on 'older workers': i) employers tend to perceive mature age workers as less capable than younger ones in terms of such factors as physical ability, capacity for learning and adaptability to change, but superior to younger workers in such factors as commitment, reliability and corporate knowledge; ii) negative perceptions may lead some employers to not support the employment of, yet alone the ongoing development of, mature 
age workers and even to encourage their departure from the organisation; (iii) some mature age workers themselves may accept negative stereotypes about age; and iv) some mature age workers experience positive employer support.

This paper draws on data of a study of Australian older workers to investigate the extent to which they experienced the sort of age discrimination commonly reported in the literature, and whether employer attitudes influenced the extent of workplace support provided to them. It also considers the implications of these findings for human resource development policy and practice.

\section{Understanding older employees' work and learning}

The larger study, referred to earlier, comprised semi-structured interviews with workers and managers, in preparation for the development of a more extensive survey (Authors 2010). This grounded approach, in which findings emerge from inductive fieldwork (Merriam \& Simpson 1995), permits appropriate depth and scope in data gathering as it allows the researchers 'to follow up leads that show up during the interview and thus obtain more data and greater clarity of the topic being investigated' (p. 151). This was the case in the approach taken and findings reported here. These findings are from 50 interviews: 48 individual interviews and two focus groups of five and six members respectively, of workers whom would all be categorised as being older. Interviewees were identified and selected through the personal contacts of the research team and referrals by interviewees (Neuman 2000). The focus groups were 'convenience samples' based on the availability of respondents for interview. The age ranges for the overall ample of 50 informants are: 45-49: 26\%, 50-54: 26\%, 55-59: 32\%, 6-64: 13\% and 65-69: 3\%. The interviewees represented a range of occupational backgrounds, with the largest groupings being from those working in nursing, education, and state government administration. The services sector (e.g. hospitality and retail) is also represented, and there are several instances of sole employees and self-employed respondents in the informants. Overall, however, the sample was predominantly 'white-collar', and predominately engaged in work described as professional, para-professional and clerical, which has implications for the generalisability of the findings. 
The schedule for the semi-structured interviews comprised four main sections: i) the type of work and the training undertaken to support that work, ii) their experiences as older workers, iii) sources of learning outside the workplace, and iv) attitudes towards further learning. All responses were coded using NVivo qualitative software, and themes identified relevant to factors and issues in maintaining the competence of older workers. This paper reports on the data informing about their experiences as older workers in regard to age discrimination in the workplace and, in particular, whether they perceived differences between younger and older workers in opportunities for learning and for advancement, and in security of employment.

\section{Perceptions of older workers' value to the workplace}

Of the 50 respondents (including the two focus groups as entities), 38 (76\%) claimed to be unaware of any evidence that older workers were less valued in their workplaces than younger employees. Among the other 12 respondents, 7 (14\%) cited anecdotal or suspected discrimination and 5 (10\%) believed there was actual discrimination. So, immediately the claims of general age bias are brought into question here. Many of those reporting not expereincing discrimination simply dismissed this proposition with an outright 'No'. Several said there was discrimination towards older workers, but in a positive way, and one claimed the workplace depended on them: '[I]t seems when there is a crisis of any sort, it always falls back on the older worker, if you can get my drift, and it seems to get us out of a hole all the time'.

Also, and again, contrary to what might be expected from that reported in the literature, some informants commented on differences in perceptions about younger and older workers. One respondent working in a high school reported younger teachers were 'in absolute awe' of older teachers, because the latter knew so much, and another informant who is a teacher stated that older teachers acted as mentors to younger teachers. In a small consultancy firm, the two older workers were referred to appreciatively as the 'grown-ups'. A retail worker in a supermarket chain also noted the particular attributes older workers bring: 'I think the older ones are far more reliable and so you know management sort of looks to those people to be available ... you know, they're not 
likely to ring in sick of a morning because they’ve had a big night out or something like that.' There was also the recognition that older workers are needed in the workforce: 'the older worker is now a commodity that society wants to have and hang on to'.

This sentiment of valuing older workers was supported by another interviewee, whose worked in an organisation, which, she claimed, had a reputation for retaining employees, some of whom had been there 20-30 years, and 'providing they're still performing and adding value, or contributing to the organisation, they're not threatened at all'. Similarly, an informant from a professional practice suggested his valuing at work was partly because of his greater availability, as he did not have other commitments as many younger professionals did. A person in a semi-skilled role claimed older workers were more valuable to the organisation because they had a good work ethic, suggesting: 'The younger ones seem to live for one day only when I've got to live for next week'. Moreover, in referring to the recent global financial crisis, one informant stated, because of the current economic circumstances it is unlikely that older workers will seek early retirement and, as reported elsewhere by the ABS, are more likely to continue their employment well past what has traditionally been accepted retirement age.

Further to this, and again quite contrary to predictions from the literature, two respondents claimed not only were older workers highly valued, but expressed concern about whether younger workers were being treated as well as their older counterparts. In one of these workplaces there was a predominance of older workers and the respondent said that younger workers' interests had to be actively protected or they tended to get 'steamrolled'. Another informant referred to younger, and newer, workers as being more likely to be on contracts, than their older counterparts, because they had been employed more recently. As such, they may be more susceptible to the demands of their employers. Similarly, another respondent said that older workers were treated better, with the younger ones given all the less attractive tasks, 'whether they like it or not'.

In between these views is a more nuanced one from a mature-age worker: 'you must be more valued in terms of your historical knowledge, but then again you're not as valued in terms of 
your technological knowledge'. Limitations in competence with technology were mentioned by a number of respondents as distinguishing them from younger workers.

The responses of the 38 respondents could be summed up in the words of one of them: 'Mature age workers are highly valued and will continue to be highly valued'. So, against the expectations created by the literature, the data offered a far more positive portrayal of and accounts of experiences from these interviews than what might have been expected from interviewing 50 socalled workers. Indeed, what emerges through the interviews is a far more nuanced and differential scenario than one characterised by general age bias, which arises from accounts based on surveys. Yet, while these data refer to the experiences of the majority of the informants, some other respondents suggested the apparent lack of discrimination against mature-age workers in their organisations was more ambiguous.

\section{Perceptions of implicit discrimination}

Seven mature-age employees interviewed suggested that, in general, there was no obvious discrimination in their workplaces on the basis of age, and stated that there were even policies in place to inhibit any such discrimination. These informants believed, however, that there were subtle indications of employer bias against mature age employees or that their employment could be under threat as they got older. For instance, one informant reminded us that there are matters of simple personal preference - 'Oh, just like wherever you work, I think. Some people think a bit better of you than other people’.

There was also the issue of older workers who find themselves on contracts when they change employment, and the nature of contractual work bringing with it greater opportunities for being controlled by employers, including not being renewed. One informant claimed in his occupational field there was some evidence of companies downsizing and although nothing was stated explicitly, there appeared to be a pattern with many of those being made redundant would classify as older workers. As was reported by the BCA (2003), this situation may well be a common and covert practice. Another informant suggested that this kind of discrimination was accepted 
practice and employers decide to make older workers redundant, rather than try and find roles for them ("parking them somewhere"). However, beyond age alone, other reasons were proposed why employers might want or feel obliged to seek to relinquish older workers’ employment.

'I don't believe anybody is flicked because of their age, ... but somebody who has been around a long time may have a particular view and not be able to change that view because they've been here for a long time and therefore maybe they don't fit in the system'.

The interview data here suggest three emerging themes: i) an underlying fear among mature age workers about their vulnerability, ii) the possible use of redundancy to mask age discrimination, and iii) employers wanting to rid themselves of mature-age workers who appear to be inflexible. Many of these accounts indicate, albeit in different ways, that some mature-age workers are not valued to the extent that is helpful for sustaining them in Australian workplaces. At the same time, the complex of factors that emerge in shaping perceptions about older workers suggest that, it is not age bias per se, but associated factors about matters of personal preference, fixed term employment that might not favour older workers, changing needs of workplaces and perceptions of older workers not being current, and so on. However, some workers also claimed that age discrimination had been clearly demonstrated in their organisations.

\section{Perceptions of explicit discrimination}

Five respondents identified particular instances where age was the main factor in workplace decisions about employment. Several of these reported mature-age workers being made redundant because they did not fit the organisation's image. Anther suggested that they were made redundant when younger employees were not, a decision that had a powerful impact on the informant:

... they didn’t put a young one off, they put me off instead and that was happening to a lot of people over the past five years. I mean I've watched it happen, I just didn't think it would be me, but it was mainly contract workers and older ones. Like there probably would have been ten older staff made redundant in the past two years, including me. 
It was also suggested that some forms of work were not amenable for older workers. One example was front-of-kitchen work in a restaurant: 'It’s really an industry for younger, you know, people who just want to run on adrenalin and work really, really quickly and are able to work really, really quickly and as you get older you can’t sustain that sort of pace.' Another was from the marketing industry: 'advertising is seen as new and cutting edge and young and groovy; it's not about old ... The older guys are running the agencies but they're soon moved on too because you've always got a younger, brighter star coming up behind you.' In another instance, an informant declared that it was the not the sector or the person, just age bias in the ways opportunities are distributed: 'it's hard to sort of put a finger on it but younger ones are always given the opportunities but the older ones never are.’

These informants identified instances of a privileging of youth over maturity as occurring in their workplaces. Informants suggested older workers being made redundant, in the first instance because they did not fit the changing organisation's image, and in the second because the organisation apparently preferred to retrench older workers rather than younger ones in order to trim its budget. Two examples also relate age to the nature of the industry - 'it's not about old'; and the last one suggests management attitudes to age determine the opportunities available.

In sum, it is evident from these data that there is some subtlety in the sorts of comments about mature age workers being valued and differences in the opportunities available and security of employment to them. Continued employability is also premised on opportunities for learning. It follows, therefore, that the next section reports on particular responses to the question about differences in opportunities for learning and advancement, and the security of older workers' employment.

\section{Differences in learning opportunities}

The interviews sought also to identify patterns in the distribution of opportunities in the informants' workplaces, including access to learning opportunities. Strongly reported across every occupational groups was the perception that all staff, regardless of age, had equal access, especially those in 
larger organisations such as the public service, a university, and in teaching: 'it doesn't matter whether you're a beginning teacher or a mature age teacher - you're expected to make sure that you are up to date and abreast with all these changes'. In the public service, one respondent suggested that older workers may get more opportunities because they've been there long enough to 'know the system' and know what they want to learn. On the other hand, a public servant on a fixed-term contract said training was not available to him - yet, this was more to do with employment status than age.

Several workers responded to this interview question with examples of mentoring they provided in their workplaces, including a vocational teaching institution where the respondent said it could be a younger or an older worker who helps the other to learn something with which they are having a problem. This informant concluded that attitude and personality were important, a response that was rehearsed by a school teacher who spoke of some colleagues just waiting for their redundancy package, and her own experience of helping younger teachers but at the same time 'I actually get energy from them because they renew in me the reason I began teaching all those years ago.' Also in a mentoring role was a person working in a social organisation with a small staff of permanents and casuals, to whom the younger ones came for advice: 'I'm not smarter than anybody else; it’s just experience I think.’

Some respondents proposed that although opportunities for learning were available for all workers, it was their attitudes about their capacities that determined if these opportunities were taken up. For example, one acknowledged that the offer was always there, but 'Why should I go and do a manager's course when I'll never use it', and another said she had not embraced the use of computers in the workplace because 'I'm 65, so it's hardly an issue, you know, I'll be gone'. Although they seemed to regard it as inevitable, some older nurses raised coping with new technology as something that was being resisted ('a scary thing'). Another informant from a large organisation stated older workers did not always take up the opportunities available around learning about new information technology. 'It is best', said another, 'to let workers continue working as long as they want to but to go on doing what they were doing because it is 'hard to teach an older 
dog new tricks'. One respondent suggested that while younger people got more opportunities to learn in their organisation, he did not see this as discriminatory because the older worker already knew so much more, and that it was natural that younger people were more likely to be learning. A person working in a small organisation with fewer than 10 employees said the organisation did not provide opportunities - a worker would need to initiate any learning

However, some mature age workers saw their employer as the gatekeeper of learning opportunities. One claimed that younger workers with any initiative were sent off to training ahead of older workers, 'probably because they think we're going to get out of here soon'. A senior bank worker stated he had never been nominated to do a course, although younger ones seemed to be 'forever' going on one. He reported that this situation was because once workers reach a certain level in the organisation 'they assume they have somebody good enough'. Another respondent proposed that younger workers underwent more training because they were more compliant, and less likely than older workers to ask why they needed to do the training.

The responses about whether there were perceived differences between the learning opportunities for older and younger workers can be categorised into four different types: i) those where all staff had equal access, ii) those where there was a mentoring role, iii) those related to the individual attitudes of workers, including towards technology, and iv) those based on employer attitudes. There is also an indication that the status of the employment and the size of the organisation are influential factors, alongside issues of age per se.

\section{Differences in opportunities for advancement}

The question about differences in opportunities for advancement was clearly more relevant to those working in larger organisations, than those in smaller organisations or who were self-employed. Even where such opportunities existed, a number of informants commented that they had reached a point in their working lives where they were no longer seeking advancement. Teachers, for example, spoke of having already decided to stay in the classroom rather than apply for an administrative position, even where the latter option had been suggested to them. Another 
respondent said: 'I guess the perception is that if an older worker was going to leap into that next level ... they would have done so 15 years earlier.' There were also other factors at play in different industries: capped pay rates preventing younger workers moving into higher level positions, and older ones staying on in senior positions and therefore holding younger workers back, whereas in a bank 'they're all being appointed at 40 years of age to be groomed for five or ten years to become the next CEO.' There were also opposing views: that older people get promoted because they are more likely to stay with the organisation, and that younger ones are favoured over older for promotion, because 'they get more out of them' or, in another instance because of young people’s ability with technology. Another informant suggested that there was a perception in society that younger people make better informed decisions, whereas a mature age worker thought there were more opportunities for her 'because of the credibility of the work I do.'

Of those in professional occupations, two respondents related advancement to possession of qualifications, one woman attributed it to being gender-based in her workplace (85\% male management), another informant claimed promotion was based on a particular manager's bias, and another suspected that there was 'a fair bit of cronyism'. One mature age worker interviewed put quite a different interpretation on the issue: 'For a younger person you might call it advancement, but for somebody in my age group it's a matter of are there opportunities for changes in your employment that would actually suit you.’

In sum, a number of quite distinct positions were advanced in response to this question which indicated different experiences and provisions for opportunity. The strongest was the case that by 'mature age', many workers had decided whether they wanted promotion or not and some were happy to stay in a role in which they were comfortable. Younger people were generally held as being regarded as being more likely to be promoted because they would be with the organisation longer or they were more capable with technology, but there were examples of exceptions to this among older workers. In a few cases, employer intervention, or lack of it, was also seen as contributing to advancement opportunities, which may not necessarily have been age related. 


\section{Security of employment}

Finally, as with advancement, the question of security of tenure also attracted diverse responses. A number of respondents, particularly in the public service and teaching, indicated they had permanency, but that younger workers tended to be employed on contract, and some respondents were concerned about the vulnerability of those younger and contracted employees. On a related matter, one respondent noted people over 60 or even 65 on three year contracts at a university who might be at risk if their contract ends, while at another university, an older worker noted the lack of younger academics to replace ageing ones, and suggested 'demographics seem to have a lot to do with the regard in which you're held'.

Two informants linked employers’ attitudes towards older workers purely in terms of costs and benefits - the higher the pay and benefits; the more likely it was the older worker would go first. Another informant referred to a government department where they wanted to bring in a new team and 'white-anted' some really good workers. An opposing view from two other respondents was that it cost too much to pay out an older permanent worker, so the employer tended to move such workers aside (i.e. 'park them') if they wanted to get rid of them, and wait for the employee to leave, as a teacher observed:

'I would hesitate to show any kind of frailty. I need to be fitter than the next person, I need to be bright-eyed and bushy tailed, seen to be absolutely coping $1000 \%$, and I wouldn't ever trust the system if I showed a weakness.'

Another teacher proposed that wanting to change the conditions of employment to suit personal preferences, e.g. to move to part-time employment, might be a bigger threat to employment than age. In a hospitality business, a mature age worker claimed it was up to the individual whether a job was safe or not, but observed that permanent employees were in a much stronger position than casual staff, a view supported by a mature age person in a small business, who saw her experience as an advantage if people were put off.

As for those self-employed: one respondent said security of employment was up to her own efforts, and a person working in medicine said that getting work was never a problem. Another 
respondent said her employer did not differentiate, but that she personally probably needed security of employment more than a younger person. Further, an informant in a hospitality organisation that employed both permanent and casual workers claimed that younger employees were not as committed to working as older workers, further complicating simply age-based decisions about employment.

Overall, the status of employment - permanent or contract - seems to be an important factor identified by respondents in relation to security of employment. There are also indications of being vulnerable for those workers who conclude that their abilities may be unfairly compared with those of younger workers.

\section{Discussion: valuing older workers}

Some conclusions drawn from comparing the findings are now advanced, using the four themes identified at the end of the literature review as 'propositions'. In each section below, the proposition is followed by the response premised on the interview data.

i) Employers tend to perceive mature age workers as less capable than younger ones in terms of such factors as physical ability, capacity for learning and adaptability to change, but superior to younger workers in such factors as commitment, reliability and corporate knowledge.

The strong and consistent response from the mature-age workers interviewed was that they were not regarded as less capable than younger workers. They consistently reported that they were valued for their experience and commitment, and some stated that younger workers looked up to them and regarded them as mentors. A few of the mature-age workers were disparaging of the work ethic of younger colleagues. However, there was a small proportion of workers who claimed they were in an industry where youthfulness was seen as a positive characteristic or who believed that they had lost their jobs or were in danger of losing their jobs because as older worker they were perceived as not fitting the current corporate image. 
ii) Negative perceptions may lead some employers to not support the ongoing development of mature age workers and to encourage their departure from the organisation.

A number of factors seem to be at work in determining the extent to which older workers have access to ongoing development opportunities. In professional occupations, such as teaching and nursing, there are mandatory requirements for all staff, regardless of age, and also changes in the nature of the work (e.g. curriculum changes, technological advances) that mean all employees need to keep themselves current in their work knowledge to continue doing their job properly. Also, there are requirements in some professions, such as teaching, for employees to undertake a minimum amount of continuing professional education, so employers are obliged to support them in those endeavours.

However, there were also some perceptions in other occupations that younger people were the first to be offered training opportunities, and a belief that this demonstrated the enactment of age bias. In some instances, the older workers interviewed were not concerned by this asymmetrical distribution of opportunities because they believed: a) they did not need more training or b) at this stage of their working lives the outcome did not justify the effort, or c) it was more appropriate for younger workers to receive more training because they needed it and could apply it for a longer time. In some cases, employment status (e.g. fixed term) may be more important than age is the distribution of training opportunities.

iii) Some mature age workers themselves may accept negative stereotypes about age.

All respondents seemed to have strong self-perceptions of their capabilities as workers, although there were occasional mentions of 'slowing down'. Given that few of the respondents were employed in heavy manual labour, change in physical ability was only occasionally mentioned, and not always in relation to themselves. The area mentioned a number times as a discriminating factor between young and old was the use of technology, and in a few cases, particularly among older nurses, there appeared to be some anxiety and even resistance to changing to a computer-based approach to some tasks, but this was not a strong pattern.

iv) Some mature age workers experience positive employer support. 
As noted above, a key finding was that over three quarters of the respondents reported being strongly supported by their employers and did not believe there was discrimination in their workplaces on the basis of age. Nevertheless, even among respondents who reported there was no discrimination, occasional indications of uncertainty about employer attitudes to their age, and beliefs emerging that they needed to be seen to be performing well and coping with change. However, there were conflicting views on whether older or younger workers would be dismissed first in the event of any layoffs.

It might have been expected from what is proposed in the literature that these interviews would have revealed a stronger pattern of age bias in these workers experiences. However, this was largely not reported as being the case. For example, working in an occupation where practitioners were in short supply (e.g. nursing) meant that you would always be treated reasonably, regardless of your age. Then, there were occupations that were more or less suited to workers who were older (e.g. counselling, professional work) and some that were more aligned to younger workers (e.g. chefs working in restaurants, advertising). Within particular occupations, there are also a range of economic factors that likely play out, more in recessionary times than in times of plenty and higher demand for employment.

There were also concrete examples reported of where younger workers are more disadvantaged than older workers in securing tenured work. Mixed in here were also a range of personal factors associated with age, interest, skill levels, occupational status etc that likely shaped how older workers are perceived and responded to. Consequently, rather than age-bias alone, there are a range of factors that shaped these workers' capacity to engage in working lives as productive as they desired. These personal factors emerged through the data and extended from being interested to develop further their work, to want to engage in new forms of work etc.

\section{Conclusion}

As proposed above, not all older workers are positioned as being last resort workers either by their employers, peers, and, it seems, themselves. These workers did not present as those who were disempowered in their workplaces and helpless in the face of new workplace challenges. Quite the 
opposite appeared to be the case. However, it seems a more nuanced and contrasting set of findings emerge from our interviews and focus groups with these kinds of workers, than those from anonymous surveys of such workers. Much of the predictions from that literature simply were not upheld. Against expectations, our informants reported little in the way of explicit age-related bias in the conditions of employment, and opportunities for advancement and further development. Although our sample was limited to 50 interviews, and has particular characteristics and featured mainly paraprofessional and professional workers, the contrast between what is reported in the literature, often premised on surveys, and our data premised on interviews is quite distinct.

The findings show that we need to be wary of generalisations about the extent to which older workers are discriminated against in the workplace, supporting Duncan's (2003) contention that research may be looking for proof of ageism rather than examining its extent or impact. In our study, the majority of the mature age workers interviewed did not perceive such discrimination in the mainly 'white collar' jobs in which they were employed. On the other hand, a small number of respondents could identify instances of perceived discrimination, either direct or indirect, so we also need to be aware that in some workplaces older workers are not valued as highly as younger ones. In between, we find a range of more nuanced responses: the sort of 'covert' discrimination the BCA (2003) warned about; the expectations by some older workers that younger people will be given more opportunities for training and promotion because the return on investment is likely to be greater for younger workers, as Drew and Drew (2005), Ranzijn (2005) and the OECD (2006) found; and the dichotomy between espoused policy and human resources practice, suggesting there is a tension in some workplaces between the depreciation model and the conservation model that Yeatts, Folts and Knapp (2000) identified.

The challenge for human resource development professionals is to recognise the various elements in the workplace that may be perceived as age discrimination, and to develop policies and practices that recognise the nuances, taking into account the nature of the occupations and the individual needs and aspirations involved. 
Acknowledgements: The research team would like to thank the interviewees who so willingly gave their time for this project, which is funded by the Australian Research Council.

\section{References}

Australian Bureau of Statistics, (2008). Population projections - a tool for examining population ageing. Australian social trends series, catalogue no. 4102.0, 15 June, ABS, Canberra.

Australian Bureau of Statistics, (2007). Labour force participation - an international comparison. Year Book Australia, catalogue no. 1301.0, 7 February, ABS, Canberra.

Bittman, M., Flick, M., and Rice, J. (2001). The recruitment of older Australian workers: a survey of employers in a high growth industry. Report for Department of Family and Community Services. Sydney: Social Policy Research Centre, UNSW.

Business Council of Australia, (2003). Age can work: A business guide for supporting older workers, Melbourne: BCA.

Claes, R. \& Heymans, M. (2008). HR professionals' views on work motivation and retention of older workers: a focus group study. Career Development International. 13 (2), 95-111.

Drew, J., and Drew, M. (2005). Employing mature age workers: Benefits and barriers. National Seniors Research Bulletin, 1(3).

Duncan, C. (2003). Assessing anti-ageism routes to older worker re-engagement. Work, Employment and Society, 17 (1), 101-120.

Encel, S. (2003). Age can work: the case for older Australians staying in the workforce. A report to the Australian Council of Trade Unions and the Business Council of Australia.

Gringart, E., Helmes, E., \& Speelman, C. (2005). Exploring attitudes toward older workers among Australian employers: an empirical study. Journal of Aging and Social Policy, 17(3) 85-103.

Hovenden, D. (2004, April). Fishy memories on ageing workforce crisis. Human Resources Magazine, retrieved 18 June 2008 from www.humanresourcesmagazine.com.au/articles/15/0c019a15.asp. 
Howell, S., Buttigieg, D., and Webber, W. (2006). Management attitudes to older workers in the retail sector. Monash Business Review, 2(3), 1-10.

Jorgensen, B. (2004). The ageing population: Implications for the Australian workforce. Sydney: Hudson Global Resources and Human Capital Solutions.

McGregor, J. \& Gray, L. (2003). Older worker employment transition. Palmerston North, New Zealand: Massey University.

McGregor, J. (2007). Employment of older workers. Retirement Commissioner's 2007 Review of Retirement Income Policy. Human Rights Commission, New Zealand.

Merriam, S. \& Simpson, L. (1995). A guide to research for educators and trainers of adults, Malabar, Florida: Krieger Publishing

Neuman, W. L. (2000), Social research methods, Boston: Allyn and Bacon,

Organisation for Economic Co-operation and Development, 2006, Live longer, work longer: A synthesis report, retrieved 29 July 2008, from www.oecd.org/dataoecd/32/50/36218997.pdf.

Ranzijn, R. (2005). Discrimination against the older worker: psychology and economics, Seminar paper, 'Of working age', May, Sydney: Human Rights and Equal Opportunity Commission, retrieved 12 August 2008 from http://hreoc.gov.au/age/workingage/speeches/ranzijn.html.

Reserve Bank of Australia. (2007, September). Trends in employment and labour supply. Reserve Bank Bulletin, Melbourne.

Steinberg, M., Donald, K., Najman, J., Skerman, H. (1996). Attitudes of employees and employers towards older workers in a climate of anti-discrimination. Australian Journal on Ageing, 15(4), 154-158.

Taylor, P. \& Walker, A. (1998). Employers and older workers: attitudes and employment practices. Ageing and Society. 18, 641-658.

The Treasury. (2004). Australia's demographic challenges. Canberra: The Treasury - Social policy division.

Yeatts, D., Folts, W.E. \& Knapp, J. (2000). Older workers' adaptation to a changing workplace: employment issues for the $21^{\text {st }}$ century. Educational Gerontology, 26, 565-582. 